\title{
Atypical pyoderma gangrenosum following total knee replacement surgery - First report in dermatologic literature *
}

\author{
Pioderma gangrenoso atípico após artroplastia total do joelho - Primeiro relato \\ na literatura dermatológica
}

\author{
Shyam B. Verma ${ }^{1}$
}

\begin{abstract}
An atypical pyoderma gangrenosum mimicking a post surgical cutaneous and subcutaneous infection is being reported for the first time in international literature after knee replacement surgery with the operation site being the starting point of pyoderma gangrenosum. Orthopedic surgeons and general surgeons should be aware of the existence of this disease and its association with surgical trauma.

Keywords: Arthroplasty, replacement, knee; Pyoderma gangrenosum; Wounds and injuries/surgery

Palavras-chave: Artroplastia do joelho; Ferimentos e lesões; Ferimentos e lesões /cirurgia; Pioderma gangrenoso

Resumo: Um pioderma gangrenoso atípico, similar a uma infecção cutânea e subcutânea pós-operatório, está sendo relatado pela primeira vez na literatura mundial, depois de realização de artroplastia do joelho, tendo como foco inicial o local da cirurgia. Cirurgióes ortopédicos e gerais devem estar cientes da existência dessa doença e de sua associação ao trauma cirúrgico.

Palavras-chave: Artroplastia do joelho; Ferimentos e lesões; Ferimentos e lesões /cirurgia; Pioderma gangrenoso
\end{abstract}

\section{INTRODUCTION}

A 72 year old woman referred by a knee replacement surgeon for what was thought to be an advancing infection was seen in this clinic. She had undergone a total knee replacement. On the third day of the surgery she complained of a bullous eruption at the lower end of the vertical incision with some pain. The surgeon saw her and found nothing wrong related with the knee implant. However a few days later an eruption was noticed with a rapid break down of the skin and was advancing inferiorly. She was given injectable cefotaxime and metronidazole for 5 days. There was no response and the wound had extended almost till the ankle. Around this time she developed an erythematous and painful soft nodule on the mid thigh which the surgeon thought was a developing abscess which was incised and drained. This site failed to granulate and in fact rapidly started sloughing till it evolved into an excruciatingly painful ulcer. At this point a dermatologic opinion was sought. There was a large, superficial ulcer extending from the knee surgery incision site to the anterior ankle with a granulomatous base, bleeding from many sites within the huge area and yellowish crust in others.(Figure 1) There was a grayish blue border around the ulcer. There was an

\footnotetext{
Aprovado pelo Conselho Editorial e aceito para publicação em 25.8.2009.

* Study carried out Nirvana Skin Clinic, Makarpura Road, Vadodara 390 009, Gujarat, India.

Conflict of interest: None/Conflito de interesse: Nenhum.

Financial funding: None / Suporte financeiro: Nenhum.

Director, International Society of Dermatology.

Member, International Advisory Board, Winter Academy of Dermatology.

Hon. Dermatologist To H.E. The Governor of Gujarat State, India.

Adjunct Associate Professor, University of Pennsylvania, Philadelphia, USA

Clinical Associate Professor, University of Virginia, Charlottesville, USA

Clinical Assistant Professor, SUNY at Stony Brook, USA.

CC2009 by Anais Brasileiros de Dermatologia
} 


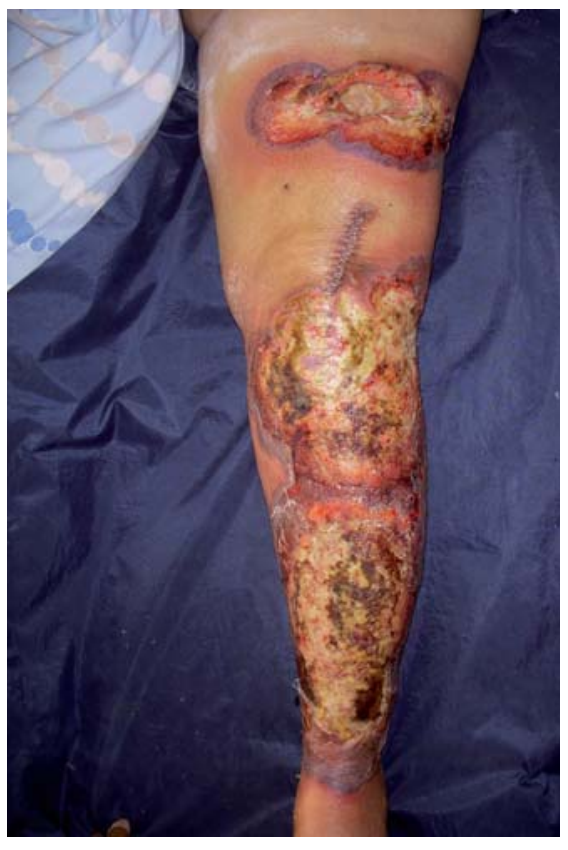

Figure 1: Atypical

Pyoderma gangrenosum appearing at and extending from the site of the total knee replacement surgery

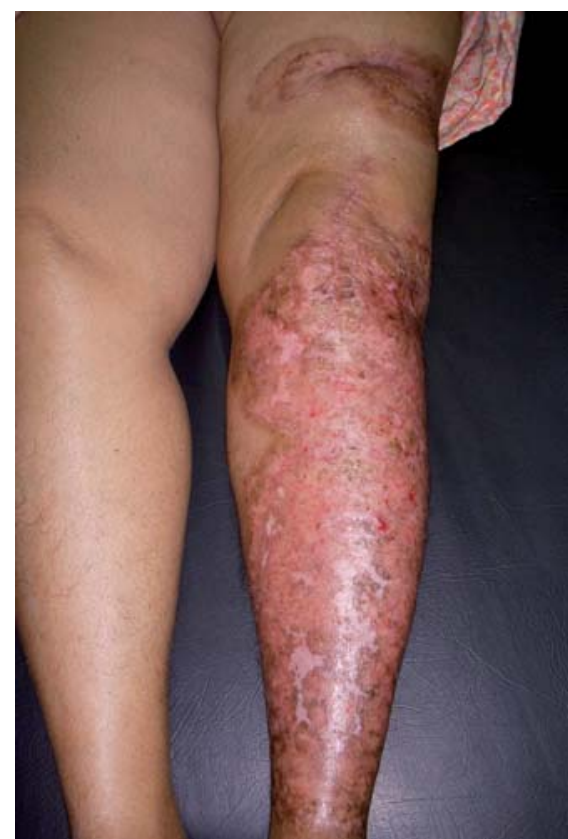

Figure 3: Complete healing of the ulcer excruciatingly painful, deep, 4"x3" ulcer on the mid thigh with a dirty purulent base exposing the underlying muscle. (Figure 2) It was surrounded by a bluish grey border. She had no constitutional signs and symptoms. She had no vasculitis or arthritis. She was diabetic and hypertensive. All relevant parameters were normal and ESR was $40 \mathrm{~mm}$. Repeated gram stains and cultures had been done by the surgeons and the cultures grew staphylococci. Cephalosporins, flouoroquinolones, amikacin, metronidazole, etc had been tried unsuccessfully. At this point the possibility of a superficial atypical variant of pyoderma gangrenosum was entertained. The patient was not subjected to a biopsy for the fear of facing the possibility of

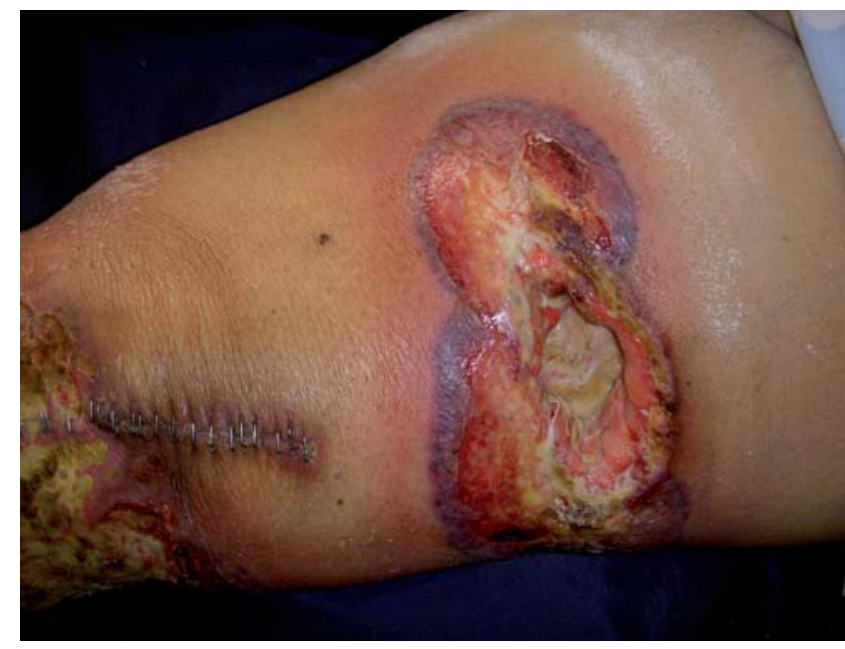

FIGURE 2: Iatrogenic Pathergy occurring at the satellite lesion of PG which was drained surgically by the treating surgeon pathergy induced by the procedure. $30 \mathrm{mg}$ oral prednisolone was given orally for a month and was eventually tapered down. Colloidal dressings were applied regularly. The ulcers healed and the patient is in remission for 10 months. (Figure 3)

\section{DISCUSSION}

Pyoderma gangrenosum (PG) characterized by dramatic ulceration of the skin and is considered to be brought about by abnormal neutrophil chemotaxis as the primary process. ${ }^{1}$ There are three distinct types of PG. ${ }^{2}$ The first and the most commonly encountered one is Classic PG. The atypical PG has more superficial ulcers or erosions with a blue gray, bullous border but is found usually on the hands, arms or face. The third is peristomal $\mathrm{PG}$.

This is an example of atypical PG characterized by rapidly spreading superficial ulceration, bullae formation at the edges, pain, bluish borders, non response to various antibiotics and immediate and dramatic improvement upon administration of oral prednisolone. ${ }^{3}$ Atypical PG is many times diagnosed as a necrotizing subcutaneous infection or cellulitis as seen in this case. ${ }^{4}$ Systemic associations of classic PG like inflammatory bowel disease, myeloproliferative disorders and inflammatory arthritis were absent. Those with atypical PG like myelogenous leukemia, myelodysplastic disorders, refractory anemias, IgA paraproteinemia, were also absent ${ }^{5}$ Also, a satellite lesion of PG developing on the thigh was mistakenly incised by the surgeon and led to pathergy which can develop with minor injuries including cuts or may follow even needle stick injuries or surgery. ${ }^{6}$ 
This is the first time that atypical pyoderma gangrenosum following the trauma of a total knee replacement surgery has been described in international dermatologic literature.

Pyoderma gangrenosum can uncommonly occur following surgery of any nature and should be included in the differential diagnosis of extensive, rapidly spreading ulcerative processes especially after surgical procedures.

\section{CONCLUSION}

Pyoderma gangrenosum is known to be initiated at the site of surgical trauma. In this case it was at the site of knee replacement surgery incision. Pathergy was demonstrated by the act of surgeon trying to incise what he thought was an abscess but was in fact a satellite lesions of pyoderma gangrenosum. Many surgical colleagues treat whatever happens after surgery as a post surgical infection and the patient is loaded with unnecessary antibiotics IV and orally. It happened in this case too and finally the patient responded very favourably to low dose prednisolone for an adequate length of time with regular collagen dressings.

\section{Acknowledgement: I}

wish to thank Dr. Sheetal Vaidya, Knee replacement surgeon and Dr. Sandeep Sharma, Plastic surgeon for their interest and help.

\section{REFERÊNCIAS}

1. Callen JP, Jackson JM, Pyoderma Gangrenosum: An update. Rheum Dis Clin North Am. 2007;33:787-802

2. Powell FC, Collins S. Pyoderma gangrenosum. Clin Dermatol. 2000;18:283-93.

3. Quimbly Sr, Gibson LE, Winkelmann RK. Superficial granulomatous pyoderma: clinicopathologic spectrum. Mayo clin Proc. 1989;64:37-43.

4. Mahajan AL, Ajmal N, Barry J, Barnes L, Lawlor D. Could your case of necrotising fascitis be Pyoderma gangrenosum? Br J Plast Surg. 2005;58:409-12.

5. Bennet ML, Jackson JM, Jorizzo JL et al. Pyoderma gangrenosum. A comparison of typical and atypical forms with an emphasis on time to remission. Case review of 86 patients from 2 institutions. Medicine. 2000;79:37-46.

6. Banga F, Schuitemaker N, Meijer P. Pyoderma gangrenosum after caesarean section: a case report. Reprod Health. $2006 ; 3: 1-5$.
ENDEREÇO PARA CORRESPONDÊNCIA / MAILING ADDRESS:

Shyam B. Verma

18 Amee Society

Diwalipura

Vadodara 390015 India

e-mail: skindiaverma@gmail.com

Como citar este artigo / How to cite this article: Shyam B. Verma. Atypical pyoderma gangrenosum0. Dermatofitoses podais em futebolistas. An Bras Dermatol. 2009;84(6):689-91. 